\title{
EUS-guided mucosectomy for gastrointestinal cancer
}

\author{
J. M. Miquel, R. Abad' ${ }^{1}$ J. Souto ${ }^{2}$, R. Fabra, M. Vila, D. Bargalló, J. L. Vázquez-Iglesias ${ }^{2}$ and \\ M. J. Varas Lorenzo ${ }^{1}$

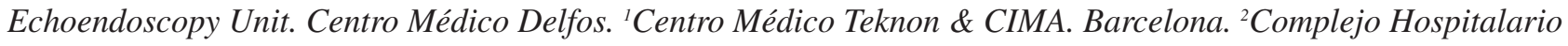 \\ Universitario “Juan Canalejo”. A Coruña, Spain
}

\begin{abstract}
Introduction: the only way of improving prognosis and survival in gastrointestinal cancer is early diagnosis, with intramucosal localization as confirmed by endoscopic ultrasonography (EUS) or $20-\mathrm{MHz}$ miniprobes (MPs) (T1) being most appropriate. Endoscopic mucosal resection (EMR) has proven effective in the treatment of this sort of lesions.

Patients and method: in a group (18 cases) with 15 cases of superficial gastrointestinal cancer and 3 cases of severe gastric dysplasia, 9 cases (3 esophageal, 4 gastric, 2 rectal) underwent a classic EMR following EUS or a 7.5- and $20-\mathrm{MHz}$ miniprobe exploration.

Results: ultrasonographic studies showed a T1 in all but one esophageal case (Tis), and in both gastric dysplasias, with no changed layer structure being demonstrated in the latter (T0).

No complications arose with classic EMR, and all 9 patients are alive and free from local or metastatic recurrence, except for one esophageal case, which recurred distally to the esophageal lesion (metachronous).

Conclusions: echoendoscopically-assisted EMR is a safe, effective technique in the endoscopic management of superficial gastrointestinal (esophageal, gastric, colorectal) cancer. Recurrence most likely depends upon cancer multiplicity.
\end{abstract}

Key words: Superficial cancer (early cancer). Endoscopic ultrasonography. High-frequency miniprobes. Mucosectomy or endoscopic mucosal resection.

Miquel JM, Abad R, Souto J, Fabra R, Vila M, Bargalló D, Vázquez-Iglesias JL, Varas Lorenzo MJ. EUS-guided mucosectomy for gastrointestinal cancer. Rev Esp Enferm Dig 2006; 98: 591-596.

Recibido: 07-08-05.

Aceptado: 21-03-06.

Correspondencia: M. J. Varas Lorenzo. Centro Médico Teknon. Marquesa de Vilallonga, 12. 08017 Barcelona. Fax: 934172 302. e-mail: varas@dr.teknon.es

\section{INTRODUCTION}

Gastrointestinal (esophageal, gastric, colorectal) cancer is classified according to layer involvement as superficial (early cancer), infiltrating, and then advanced cancer. In the management of gastrointestinal cancer, the only way of improving prognosis and survival is by identifying it early in its course, the most suitable stage being intramucosal localization before the development of nodal metastases. Superficial neoplasms are lesions with scant endoscopic expression, and nearly always behave with no symptoms.

Superficial esophageal cancer is defined as that confined to the mucosal and submucosal layers. Following endoscopic diagnosis using colorings or otherwise, as well as biopsies, radial 20-MHz EUS or the use of 20$\mathrm{MHz}$ or higher power transendoscopic miniprobes is attempted (1) in order to classify lesions as mucosal (m1, $\mathrm{m} 2, \mathrm{~m} 3$ ) or submucosal (sm1, sm2, sm3). Submucosal invasion entails a $50 \%$ risk for adenopathies, and a 5-year survival of around $60 \%$.

Mucosectomy or endoscopic mucosal resection (EMR) is only indicated for T1 mucosal cancers, while esophagectomy is restrained to submucosal lesions (T1sm), as $4 \%$ of such lesions have lymphatic involvement. Nevertheless, patients with submucosal T1 lesions who refuse to undergo surgery or have a seriously high surgical risk may be eligible for EMR.

Makuuchi et al. (2), in a series of 255 lesions, obtained a local recurrence rate of $2.4 \%$, with only one death from esophageal cancer after 6 months. Oyama et al. (3) reported $3.1 \%$, and Nomura et al. (4), 4\%. Shimizu et al. (5) obtained results similar to those reported by Makuuchi et al. (2).

In superficial gastric cancer, EMR may be an alternative to radical surgery when lesions are well-differentiated, intestinal-type adenocarcinomas with no ulcers, confined to the mucosa (risk of adenopathies is lower 
than $3 \%$, but goes up to $25 \%$ when there is submucosal involvement), and smaller than $20 \mathrm{~mm}$ in size. On average, $86 \%$ of patients achieve full resection (6).

Kida et al. (7) discuss a series of 246 EMRs with a radical resection rate of $68.3 \%$, and a tumor recurrence rate of $2.8 \%$, in the absence of tumor-related mortality and with few complications (7-9).

Superficial colorectal cancer is defined as the tumor invading $20 \%$ of the submucosal layer at most (10), without protrusion. Using a $15-\mathrm{MHz} \mathrm{MP}$ mucosal involvement may be told apart from sm1 and sm2-3 in $86 \%$ of cases (11). In addition to colorings (chromoscopy) and biopsies, magnification endoscopy is also indicated.

The risk for adenopathies is lower than $2 \%$ when the mucosal layer is involved, and reaches $15 \%$ when the submucosa is also affected.

Lesions smaller than $5 \mathrm{~mm}$ may be excised using biopsy forceps, polypectomy snares or mucosectomy; those greater than $5 \mathrm{~mm}$ using mucosectomy, up to $10 \mathrm{~mm}$ when depressed or $20 \mathrm{~mm}$ when flat-elevated, provided the submucosa has not been invaded.

Endoscopic therapy is considered curative when the following is met: well differentiated, no lymphatic or venous invasion, and invasion not beyond the superficial submucosas layer $(\mathrm{sm} 1)$.

\section{PATIENTS AND METHOD}

In the last few years the teams at Barcelona and $\mathrm{A}$ Coruña have diagnosed 15 cases of superficial cancer (5 esophageal, 8 gastric, 2 rectal) from 8 to $30 \mathrm{~mm}$ in size;

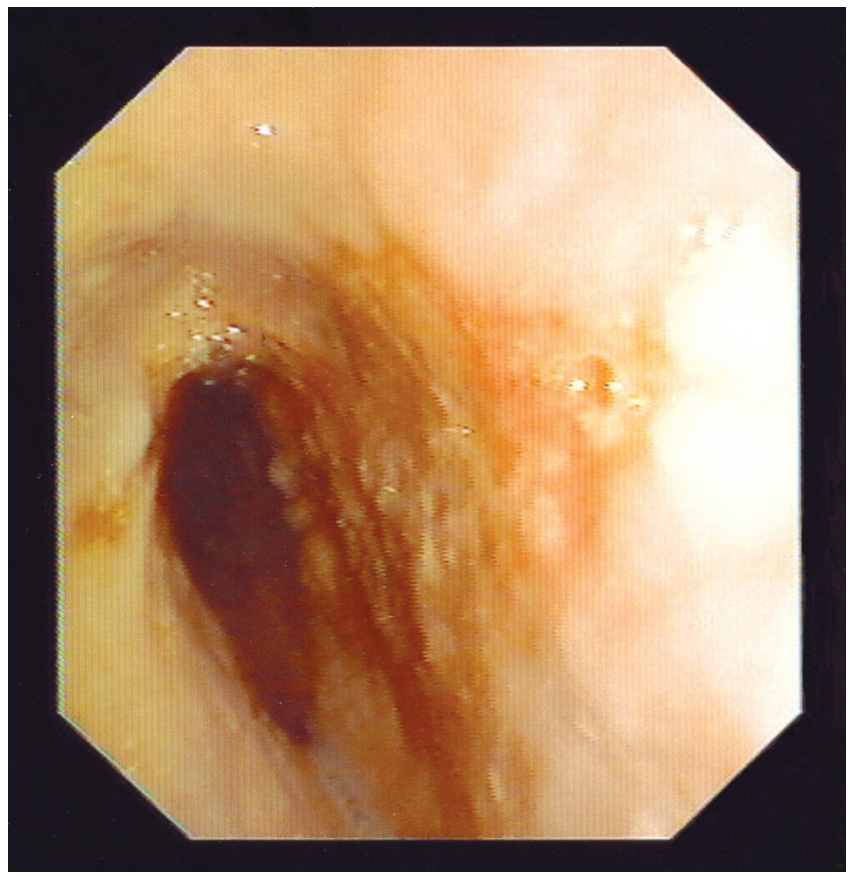

Fig. 1.- A: Endoscopic appearance of a superficial esophageal cancer A: Aspecto endoscópico de neoplasia maligna de esófago superficial. and three severe gastric dysplasias in patients from 45 to 86 years of age (X: 76 yrs), 12 males and 6 females, using EMR for 9 cases ( 3 esophageal, 4 gastric, 2 rectal), all of them following 7.5- and 20-MHz EUS. The rest were treated with radical surgery or argon gas.

Two cases of degenerated Barrett's esophagus, which also underwent mucosectomy, were not included.

EUS was performed using Olympus GF-UM 130 and 160, 7.5- and 20-MHz radial echoendoscopes, and Fuji radial and linear $20-\mathrm{MHz}$ miniprobes. We are also currently using Olympus UM-DP12-25R and 20-25R miniprobes, fitted with DPR.

The current TNM classification was used.

EMR technique: associated with submucosal injection, suction, and polypectomy.

Regardless of patient demographic data, all variables related to lesion endoscopic and echoendoscopic characteristics were included in the study.

The statistical analysis was performed using the SPSS 11.5 for Windows software package.

\section{RESULTS}

Ultrasonographic studies using EUS or MPs demonstrated a T1 neoplasm (mucosal involvemet; mucosal and submucosal involvement, only one case) in all but one cases; the exception was an esophageal tumor where no changes could be seen in layer structure (T0). The same happened for dysplasia cases (T0) (Figs. 1-3).

EMR had no complications. All nine patients are alive and free of local or metastatic recurrence after at least 6 to 24 months' follow-up; one (esophageal) case, however, re-

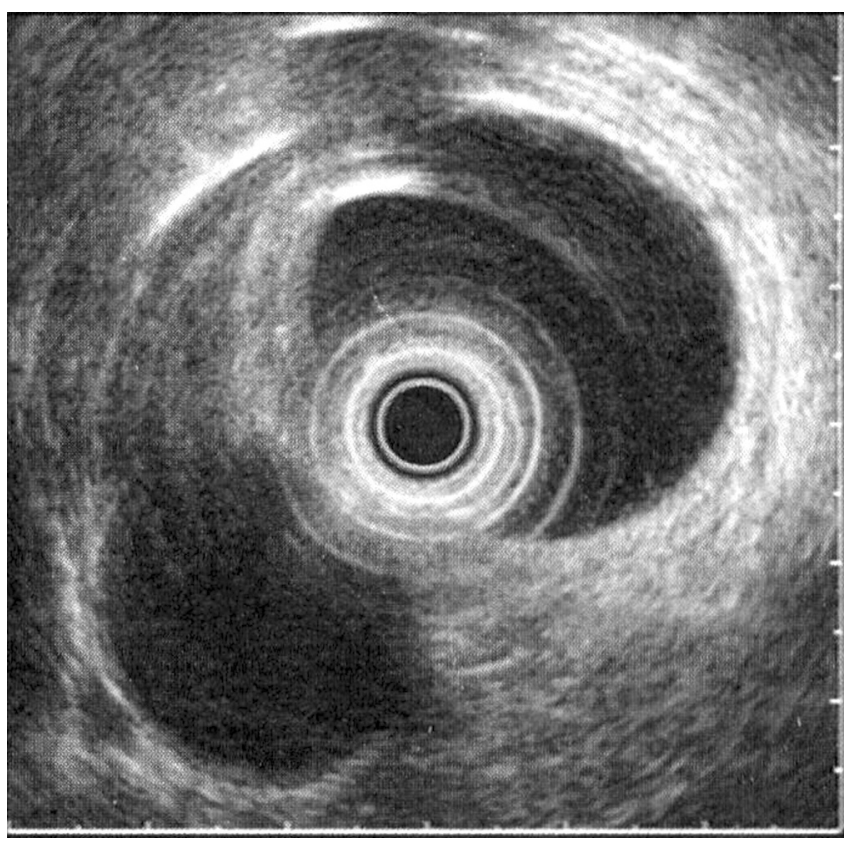

Fig. 1.- B: Normal ultrasonographic appearance (T0) using 7.5- and 20$\mathrm{MHz}$. EUS

B: Aspecto ecográfico normal (TO) con USE de 7,5 y $20 \mathrm{MHz}$. 


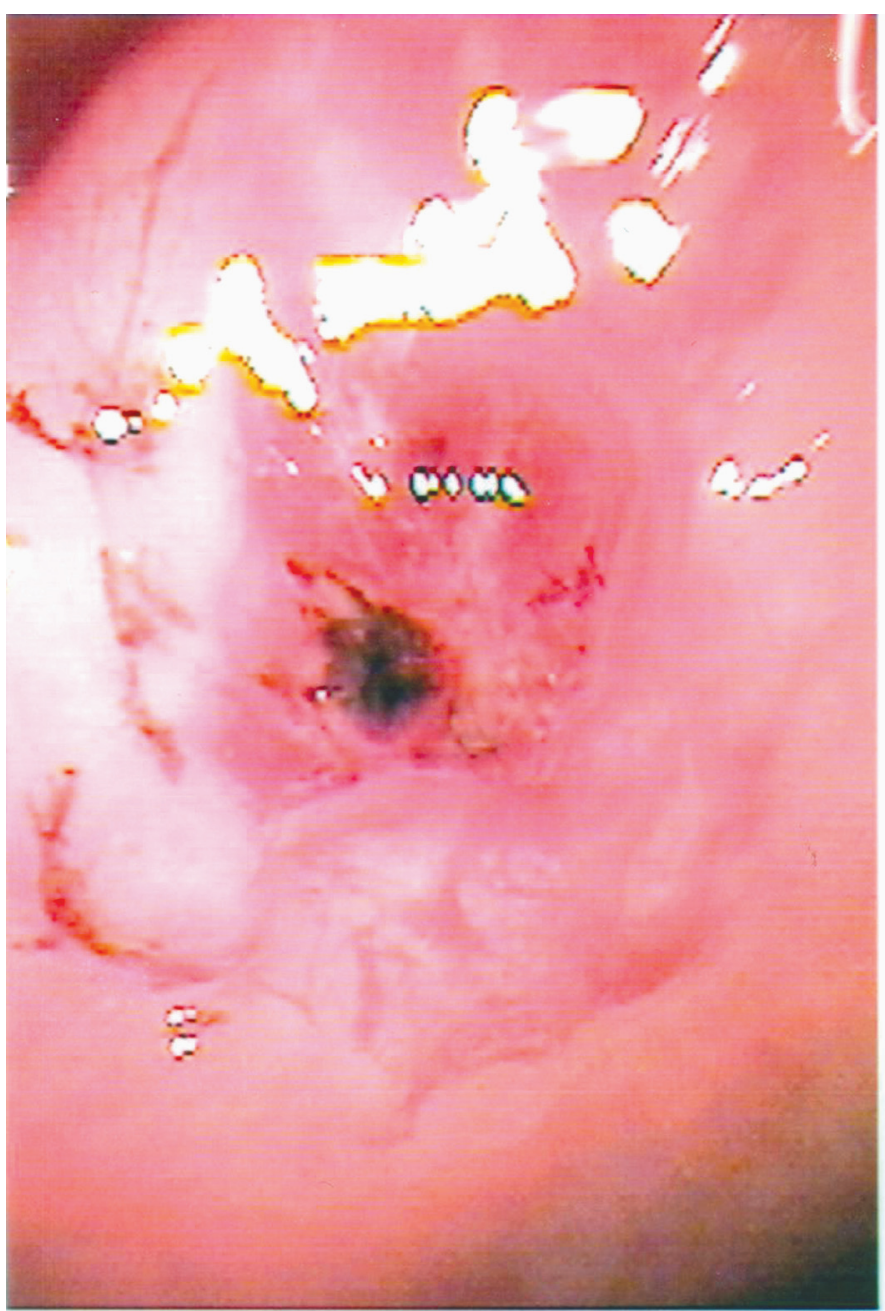

Fig. 2.- A: Endoscopic appearance of a superficial gastric cancer.

A: Aspecto endoscópico de neoplasia maligna gástrica superficial.

lapsed distally to the index lesion (metachronous?), and was managed with radiotherapy and chemotherapy.

\section{DISCUSSION}

Of the many local therapies for superficial cancer only EMR allows to obtain a resection piece for complete histopathologic examination, which in turn allows complete cure to be ensured. The same is true for uncertain lesions, adenomas, and submucosal tumors.

Local recurrence in superficial esophageal cancer amounts to $2-4 \%$ (2-5). One of our three such patients had a recurrence that was distal to the index esophageal lesion. Local recurrence seems to depend upon esophageal cancer multiplicity, and reaches 40 versus $4 \%$ for single lesions (4).

Shimizu et al. (5) diagnosed $14.6 \%$ of metachronous cancer lesions following EMR in sites more than $1 \mathrm{~cm}$ distal to the previous scar.

Survival is usually $95 \%$ at 5 years.

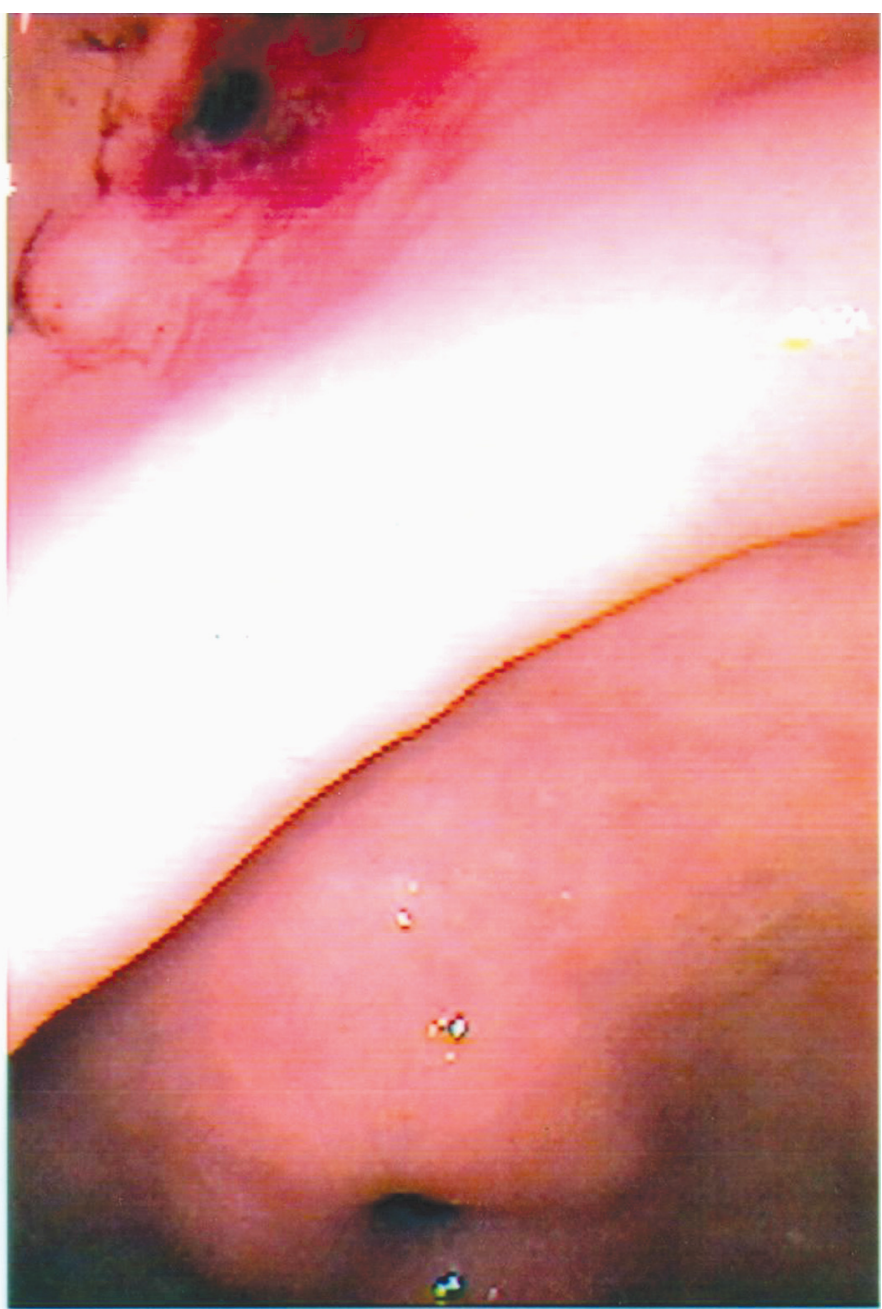

Local recurrence is also $2-4-2.8 \%$ according to the most extensive series -in superficial gastric cancer (7). Survival is also very high at 5 years. Complications (pain, bleeding, perforation) are few, below 10\% (8).

Local recurrence in superficial colorectal cancer is very low (12).

Virtual diagnoses, the newer endoscopic diagnostic methods, and the use of echoendoscopy $(13,14)$ will all increase the early identification of superficial gastrointestinal cancer; EMR will thus be increasingly common (15), and will improve survival in this type of cancer $(16,17)$.

EUS is essential for the stratification of patients with gastrointestinal (esophageal, gastric, colorectal) cancer, and the selection for EMR of those with $\mathrm{T} 0$ and $\mathrm{T} 1 \mathrm{le}-$ sions.

\section{REFERENCES}

1. Murata Y, Suzuki S, Ohta M, et al. Small ultrasonic probes for determination of the depth of superficial esophageal cancer. Gastrointest Endosc 1996; 44: 23-8. 


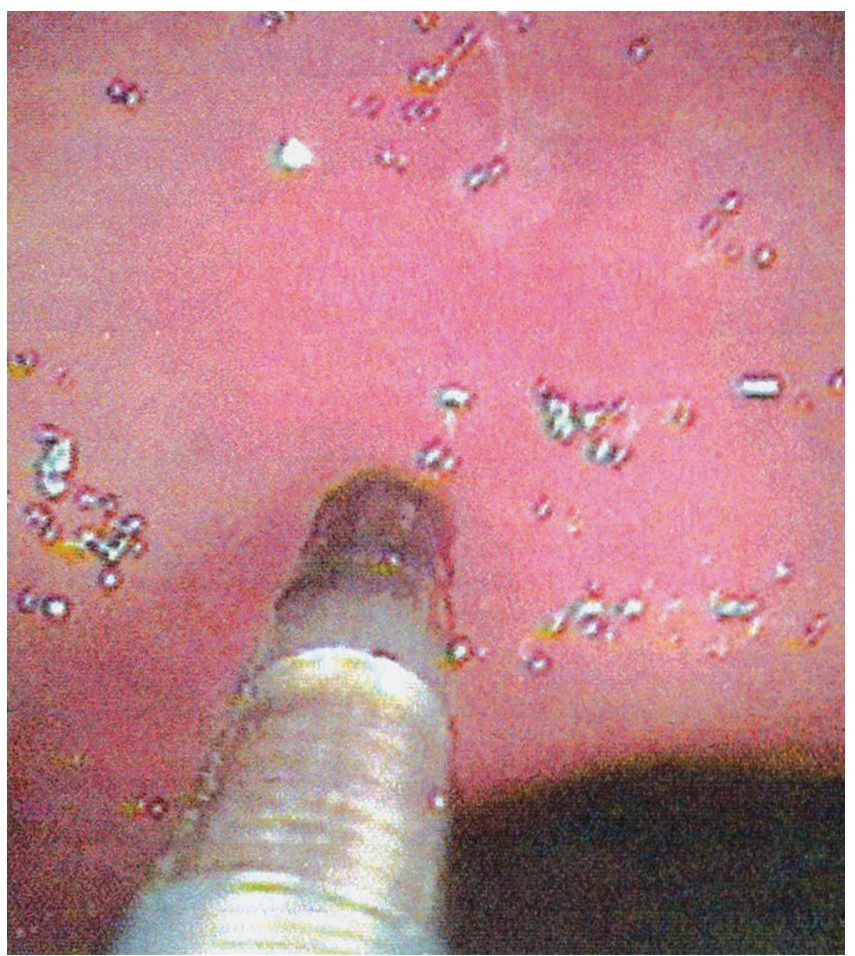

Fig. 2.- $\mathrm{B}$ : A 20-MHz miniprobe exploring this same patient.

B: Minisonda de $20 \mathrm{MHz}$ realizando la exploración del mismo caso.

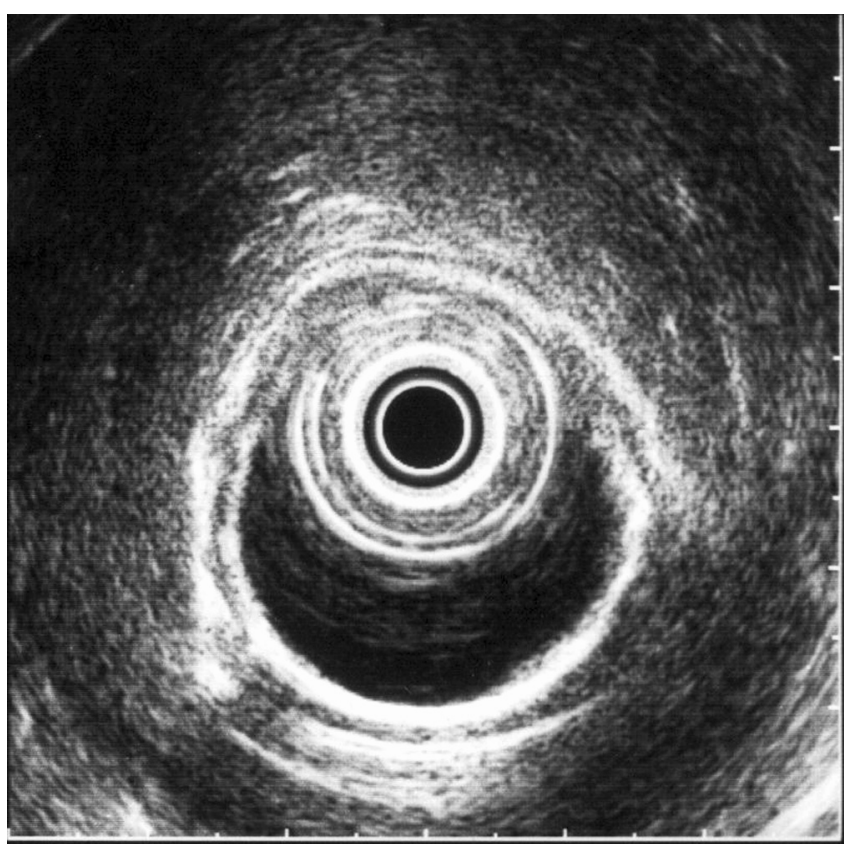

Fig. 3.- A: Gastric T1NO using 7.5-MHz EUS.

A: T1NO gástrico con USE de 7,5 MHz.

2. Makuuchi H, Shimada H, Mizutani K, et al. Analysis of long term follow up patients after endoscopic mucosal resection for early esophageal cancer- with special reference to metachronous multiple cancers. Stomach and Intestine 1996; 31: 1223-33.

3. Oyama T, Miyata Y, Okaniwa S, et al. Local recurrence of esophageal squamous cell carcinoma after endoscopic esophageal mucosal resection. Stomach and Intestine 1996; 31: 1217-22.

4. Nomura T, Boku N, Ohtsu A, Muto M, Matsumoto S, et al. Recurren-

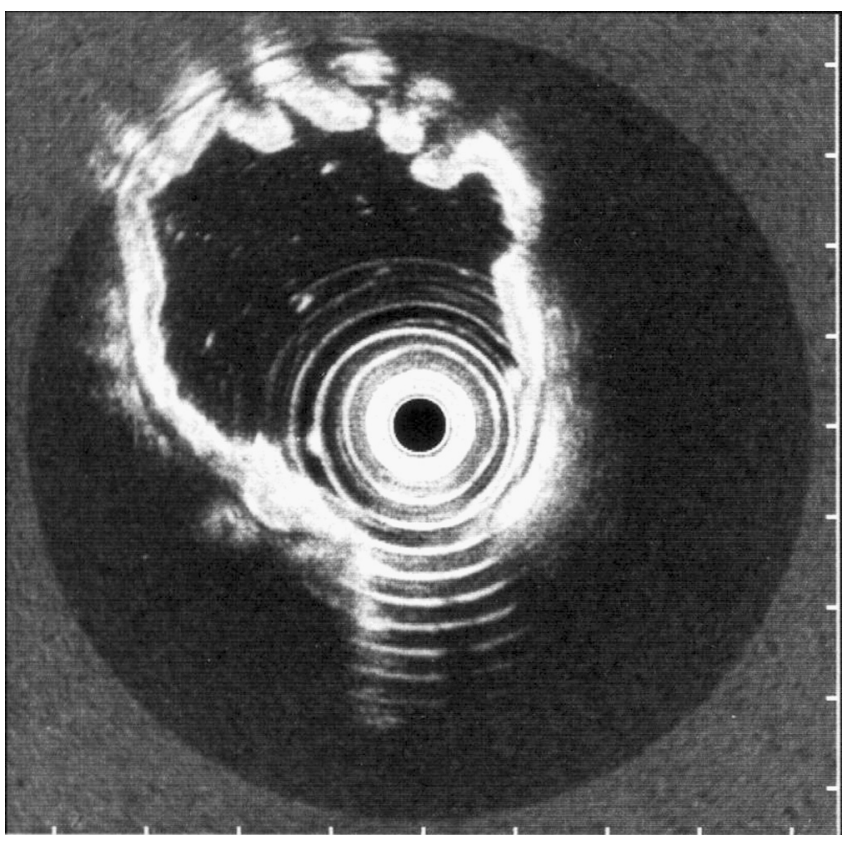

Fig. 3.- B: Gastric T1NO using 20-MHz EUS.

B: T1NO gástrico con USE de $20 \mathrm{MHz}$.

ce after endoscopic mucosal resection for superficial esophageal cancer. Endoscopy 2000; 32: 277-80.

5. Shimizu Y, Tukagashi H, Fujita M, et al. Metachronous squamous cell carcinoma of the esophagus arising after endoscopic mucosal resection. Gastrointest Endosc 2001; 54: 190-4.

6. Takekoshi T, Baba Y, Ota H. Endoscopic resection of early gastric carcinoma: results of a retrospective analysis of 308 cases. Endoscopy 1995; $25: 352-8$

7. Kida M, Tanabe S, Watanabe M, Kokutou M, Kondou I, et al. Staging of gastric cancer with endoscopic ultrasonography and endoscopic mucosal resection. Endoscopy 1998; 30 (Supl. 1): A64-A68.

8. Giovannini M, Bernardini D, Moutardier V, Monges H, Houvenaeghel G, et al. Endoscopic mucosal resection (EMR): results and prognostic factors in 21 patients. Endoscopy 1999; 31: 698-701.

9. Waxman I, Saitoh Y. Clinical outcome of endoscopic mucosal resection for superficial GI lesions and the role of high-frequency US probe sonography in an American population. Gastrointest Endosc 2000; 52: 322-7.

10. Hizawa K, Suekane H, Aoyagi K, Matsumoto T, Nakamura S, Fujishima M. Use of endosonographic evaluation of colorectal tumor depth in determining the appropriateness of endoscopic mucosal resection. Am J Gastroenterol 1996; 91: 768-71.

11. Harada N, Hamada S, Kubo H, Oda S, Chijiiwa Y, Kabemura T, et al Preoperative evaluation of submucosal invasive colorectal cancer using a $15 \mathrm{MHz}$ ultrasound miniprobe. Endoscopy 2001; 33: 237-40.

12. Inoue Y, Tezuka T, Shinohara T, Katck H, Opi I, Takasaki K. Endoscopic mucosal resection of colorectal tumor. Digestive Endoscopy 2004; 16 (1): 91-4.

13. Souto J, Martínez D, Yánez JA, Vázquez Iglesias JL. Implicaciones terapéuticas de la ultrasonografía endoscópica en la patología tumoral. En: Ultrasonografía endoscópica, Tomo II. Barcelona: Ed. Glosa; 2002. p. 84-6.

14. Fernández-Urién I, Súbtil JC, Muñoz-Navas M. Ecoendoscopia. Estado actual. Rev Esp Enferm Dig 2003; 95: 68-93.

15. Lightdale CJ. Endoscopic mucosal resection: This is our turf. Endoscopy 2004; 36: 808-10.

16. Chávez M. Tratamiento endoscópico del carcinoma gástrico precoz: de la resección mucosa endoscópica (RME) a la disección submucosa endoscópica (DSE). Rev Gastroenterol Perú 2005; 25: 76-92.

17. Kakushima N, Yahagi N, Fujishiro M, Kodashima S, Nakamura M, Omata M. Efficacy and safety on endoscopic submucosal dissection for tumors of the esophagogastric junction. Endoscopy 2006; 38: $170-4$. 